\title{
TINGKAT KEPUASAN PASIEN TERHADAP PELAYANAN KEFARMASIAN DI RUMAH SAKIT UMUM DAERAH KLUNGKUNG TAHUN 2016
}

\section{(PATIENT SATISFACTION LEVEL ON PHARMACEUTICAL SERVICE IN KLUNGKUNG GENERAL HOSPITAL IN 2016)}

\author{
FITRIA MEGAWATI $^{\bullet}$, NI PUTU UDAYANA ANTARI ${ }^{1}$ \\ ${ }^{1}$ Akademi Farmasi Saraswati Denpasar, Jalan Kamboja No. 11A Denpasar
}

\begin{abstract}
Abstrak: Pelayanan kefarmasian mempunyai peranan strategis dalam upaya meningkatkan derajat kesehatan masyarakat. Pelayanan yang kurang optimal dapat menyebabkan ketidakpuasan pasien. Pasien akan merasa puas apabila ada persamaan antara harapan dan kenyataan pelayanan kesehatan yang dapat memuaskan pelanggan, oleh karena itu penulis ingin mengetahui tingkat kepuasan pasien terhadap pelayanan kefarmasian di RSUD Klungkung.Penelitian ini merupakan penelitian yang menggunakan pendekatan analisis deskriptif yang bertujuan untuk mengetahui tingkat kepuasan pasien terhadap pelayanan kefarmasian di Instalasi Farmasi Rumah Sakit Umum Daerah Klungkung. Penelitian dilaksanakan melalui penyebaran kuesioner yang dibuat oleh I Gede Agus Handi Krisnawan dengan reliabilitas 0,947 yang berisi lima indikator yaitu reliability (kehandalan), assurance (keyakinan), tangible (berwujud), empathy (empati), responsiveness (cepat tanggap). Dari hasil perhitungan dan analisa data, pada masing-masing indikator diperoleh prosentase sebagai berikut : tangible $53,33 \%$ dengan klisifikasi cukup puas, responsiveness $28,80 \%$ dengan klasifikasi tidak puas, assurance dengan prosentase $65,88 \%$ dengan klasifikasi cukup puas, empathy 56,23\% dengan klasifikasi cukup puas, dan reliability 45,33\% dengan klasifikasi kurang puas. Disimpulkan bahwa tingkat kepuasan pasien terhadap pelayanan kefarmasian di Instalasi Farmasi Rumah Sakit Umum Daerah klungkung adalah kurang puas.
\end{abstract}

Kata kunci:pelayanan kefarmasian, Rumah Sakit Umum Daerah Klungkung, tingkat kepuasan

\section{ABSTRACT}

Abstract: Pharmacy services has a strategic role in improving community health status. Services that less than optimal can lead to patient dissatisfaction. Patients will be satisfied if there are similarities between the expectations and the reality of health services which can satisfy the customer, therefore the author would like to know the level of patient satisfaction with pharmacy services in Klungkung General Hospital. This research is the use of descriptive analysis approach that aims to determine the level of patient satisfaction with pharmacy services in Pharmacy Installation District General Hospital Klungkung. The research was conducted through questionnaires made by I Gede Agus Handi Krisnawan with 0.947 reliability that contains five indicators of reliability, faith, tangible, empathy, responsiveness. From the calculation and analysis of data on each indicator of the percentage obtained as follows: tangible $53.33 \%$ with Classification quite satisfied, responsiveness $28.80 \%$ with a classification is not satisfied, assurance with a percentage of $65.88 \%$ with a classification quite satisfied, empathy $56.23 \%$ with a classification quite satisfied, and reliability $45.33 \%$ less satisfied with the classification. It can be concluded that the level of patient satisfaction with pharmacy services in Pharmacy Installation District Klungkung General Hospital are less satisfied.

Keywords: Klungkung General Hospital, level of satisfaction, pharmacy services.

\section{PENDAHULUAN}

Rumah sakit mempunyai peranan yang penting untuk meningkatkan derajat kesehatan masyarakat. Berdasarkan UU Nomor 44 Tahun 2009 tentang rumah sakit, rumah sakit adalah institusi pelayanan kesehatan yang menyelenggarakan pelayanan kesehatan perorangan secara paripurna yang menyediakan pelayanan rawat inap, rawat jalan, dan gawat darurat (Depkes RI, 2009). Di Indonesia rumah sakit merupakan rujukan pelayanan kesehatan untuk puskesmas terutama upaya penyembuhan dan pemulihan. Mutu pelayanan di rumah sakit sangat dipengaruhi oleh kualitas dan jumlah tenaga kesehatan yang dimiliki rumah sakit tersebut. Sebagai pusat pelayanan kesehatan, rumah

•email korespondensi: f.mega83@gmail.com 
sakit harus meningkatkan mutu pelayanan termasuk di dalamnya adalah mutu pelayanan kefarmasian.Unit farmasi merupakan unit yang memberikan pelayanan langsung kepada pasien dibidang kefarmasian yang sangat menentukan derajat kesehatan masyarakat (Depkes RI, 2004).

Pasien akan merasa puas apabila mendapatkan pelayanan yang dapat memenuhi semua kebutuhan dan keinginannya. Hal ini dapat berupa kecepatan pelayanan kefarmasian dan komunikasi yang dilakukan antara tenaga kefarmasian dengan konsumen atau pasien pada saat pelayanan kefarmasian berlangsung. Semakin cepat dan tepat pelayanan suatu resep maka akan memberikan sebuah kepuasan ke konsumen atau pasien. Kepuasan merupakan hal yang sangat subyektif, sulit diukur, dapat berubah-ubah, serta terdapat banyak sekali faktor yang berpengaruh sebanyak dimensi di dalam kehidupan manusia. Subyektifitas tersebut bisa berkurang dan bahkan bisa menjadi objektif bila cukup banyak pendapat yang sama terhadap sesuatu hal (Suryawati,2004).

Pengukuran tingkat kepuasan pasien penting dilakukan sebagai konsekuensi peningkatan mutu layanan kesehatan. "Kesembuhan dan Kepuasan Anda Adalah Kebahagian Kami" itu merupakan MOTTO dari Rumah Sakit Umum Daerah Klungkung. Dimana saat ini RSUD Klungkung sedang berbenah dan meningkatkan pelayanan kesehatan agar pasien merasa nyaman dan puas berobat di RSUD Klungkung. Melalui penelitian tingkat kepuasan konsumen, pasien dapat diketahui sejauh mana pelayanan kesehatan yang telah diselenggarakan apakah sudah atau belum memenuhi harapan masyarakat.

\section{BAHAN DAN METODE}

Data penelitian disajikan dalam bentuk persentase dan diagram untuk menggambarkan distribusi dan frekuensi mengenai karakteristik responden yang terdiri dari jenis kelamin, usia, tingkat pendidikan, pekerjaan dan status perkawinan.

Dari data kuisioner yang diperoleh, dijelaskan secara deskriptif persepsi pasien terhadap masing-masing poin pernyataan pada tiap dimensi kualitas pelayanan di instalasi farmasi. Dengan instrumen kuesioner yang menggunakan sistem skoring Skala Likert, dapat dilihat pada pernyataan mana yang memiliki persepsi tertinggi dari pasien Instalasi Farmasi RSUD Kabupaten Klungkung. Rata-rata skor tiap poin pernyataan diklasifikasikan agar lebih mudah diinterpretasikan, dalam rentang rata-rata dari nilai terkecil sebesar 1 sampai dengan nilai terbesar sebesar 5 memiliki interval.
Interval $=($ Skor tertinggi - Skor terendah $) /$ Jumlah klasifikasi

$$
\begin{aligned}
& =(5-1) / 5 \\
& =0,8(\text { Mulyono, } 1991)
\end{aligned}
$$

Dengan demikian diperoleh klasifikasi nilai, yaitu dari interval nilai 1-1,8 diklasifikasikan tidak puas, interval > 1,8-2,6 diklasifikasikan kurang puas, interval > 2,6-3,4 diklasifikasikan cukup puas, > 3,44,2 diklasifikasikan puas, interval > 4,2-5 diklasifikasikan sangat puas. Dengan demikian diperoleh klasifikasi nilai Tabel 3.2 Klasifikasi Persepsi Pasien (Mulyono, 1991)

Tabel 3.2 Klasifikasi Persepsi Pasien

\begin{tabular}{cc}
\hline Interval & Klasifikasi \\
\hline $\mathbf{1 - 1 , 8}$ & Tidak puas \\
$\mathbf{> 1 , 8 - 2 , 6}$ & Kurang puas \\
$\mathbf{2}, \mathbf{6 - 3 , 4}$ & Cukup puas \\
$\mathbf{> 3 , 4 - 4 , 2}$ & Puas \\
$\mathbf{> 4 , 2 - 5}$ & Sangat puas \\
\hline
\end{tabular}

\section{HASIL}

Responden diambil berdasarkan kriteria inklusi yang telah ditetapkan. Analisis deskriptif berguna untuk memberikan gambaran mengenai karakteristik responden berdasarkan jenis kelamin, usia, tingkat pendidikan, status perkawinan, pekerjaan, dari pasien atau penunggu pasien yang datang ke di Instalasi Farmasi Rumah Sakit Umum Daerah Klungkung. Diagram pinca/lingkar digunakan untuk menyajikan data diskrit atau data dengan skala nominal dan ordinal atau disebut juga data katagori (Hastono dan Sabri, 2011).

Dari 100 responden yang menjadi sampel penelitian, responden laki-laki berjumlah $56 \%$ sedangkan responden perempuan berjumlah $44 \%$. Berdasarkan jenis kelamin responden terbanyak adalah laki-laki. Dari 100 responden yang menjadi sampel penelitian, responden yang berumur 18-24 tahun berjumlah 34 orang (34\%), responden yang berumur 25-36 tahun berjumlah 40 orang (40\%), responden yang berumur 37-48 tahun berjumlah 20 orang (20\%), dan responden yang berumur 49-60 tahun berjumlah 6 orang (6\%). Dari 100 responden yang menjadi sampel penelitian, responden dengan status perkawinan belum kawin berjumlah 48 orang (48\%) dan yang sudah kawin berjumlah 52 orang (52\%). karakteristik Berdasarkan status perkawinan, responden terbanyak adalah responden dengan status kawin. Dari 100 responden yang menjadi sampel penelitian, responden dengan pendidikan SMP berjumlah 2 orang (2\%), pendidikan SMA berjumlah 
44 orang $(44 \%)$, pendidikan D1 berjumlah 5 orang (5\%), pendidikan D3 berjumlah 25 orang $(25 \%)$, pendidikan $\mathrm{S} 1$ berjumlah 21 orang (25), dan pendidikan S2 berjumlah 3 orang (3\%). Berdasarkan karakteristik pendidikan responden terbanyak adalah responden pendidikan SMA. Dari 100 responden yang menjadi sampel penelitian, responden dengan pendidikan SMP berjumlah 2 orang (2\%), pendidikan SMA berjumlah 44 orang (44\%), pendidikan D1 berjumlah 5 orang (5\%), pendidikan D3 berjumlah 25 orang (25\%), pendidikan S1 berjumlah 21 orang (25), dan pendidikan S2 berjumlah 3 orang (3\%). Berdasarkan karakteristik pendidikan responden terbanyak adalah responden pendidikan SMA.

Dari 100 responden yang menjadi sampel penelitian, responden dengan pekerjaan mahasiswa/mahasiswi berjumlah 21 orang (21\%), pegawai swasta berjumlah 27 orang (27\%), wiraswasta berjumlah 12 orang (12\%), pegawai negeri sipil berjumlah 21 orang $(21 \%)$ tidak bekerja berjumlah 12 orang (12\%) dan lain-lain berjumlah 7 orang $(7 \%)$. Berdasarkan karakteristik pekerjaan, responden terbanyak adalah responden pegawai swasta.

Setelah dilakukan penyebaran kuesioner terhadap pasien yang menebus resep di apotek, didapat hasil atau skor dari tiap pertanyaan. Dari setiap pertanyaan tersebut dirancang pertanyaan dengan jawaban yang mendukung (favorable), dan diberi skor 5 untuk jawaban Sangat Sesuai (SS), skor 4 untuk jawaban Sesuai (S), skor 3 untuk jawaban Kurang Sesuai (KS), skor 2 untuk jawaban Tidak Sesuai (TS), dan skor 1 untuk jawaban Sangat Tidak Sesuai. (STS), dan pertanyaan dengan jawaban tidak mendukung (un-favorable), dengan skor 1 untuk jawaban Sangat Sesuai (SS), skor 2 untuk jawaban Sesuai (S), skor 3 untuk jawaban Kurang Sesuai (KS), skor 4 untuk jawaban Tidak Sesuai (TS), dan skor 5 untuk jawaban Sangat Tidak Sesuai (STS). Data yang diperoleh disajikan dalam tabel sebagai berikut: (Lampiran 3. Perhitungan Skor 100 Responden)

Dari 100 orang responden yang diberikan kuesioner tentang tingkat kepuasan pasien terhadap pelayanan kefarmasian di Instalasi Farmasi Rumah Sakit Umum Daerah Klungkung, indikator Reliability (kehandalan) memperoleh nilai rata-rata 45\% diklasifikasikan kurang puas dan memiliki persentase 55\% diklasifikasi tidak puas. Hal ini dapat diartikan para pasien merasa puas terhadap pelayanan yang diberikan di Instalasi Farmasi Rumah Sakit Umum Daerah Klungkung. Dalam indikator Responsiveness (cepat tanggap), memperoleh nilai rata-rata $29 \%$ diklasifikasikan tidak puas dan memiliki persentase $71 \%$ diklasifikasian sangat tidak puas.Dari data-data diatas, pasien merasa puas dengan ketanggapan dari pelayanan yang diberikan di Instalasi Farmasi Rumah Sakit Umum Daerah Klungkung. Untuk indikator Assurance (keyakinan) memperoleh nilai rata-rata $66 \%$ diklasifikasikan cukup puas dan memiliki persentase 34\% diklasifikasikan tidak puas. Dilihat dari data-data diatas, pasien merasa puas dengan pelayanan kefarmasian yang diberikan di Instalasi Farmasi Rumah Sakit Umum Daerah Klungkung. Indikator Emphaty (empati), mendapat nilai rata-rata $56 \%$ diklasifikasikan cukup puas dan memiliki persentase $44 \%$ tidak puas. Pasien merasa puas dengan empati yang diberikan oleh para pegawai di Instalasi Farmasi Rumah Sakit Umum Daerah Klungkung. Indikator Tangible (berwujud) mendapatkan,nilai rata-rata $53 \%$ diklasifikasikan cukup puas dan memiliki persentase $47 \%$ diklasifikasikan tidak puas. Nilai-nilai ini mengindikasikan bahwa pasien merasa puas dengan pelayanan kefarmasian yang mereka dapatkan di Instalasi Farmasi Rumah Sakit Umum Daerah Klungkung.

Secara keseluruhan dari 5 indikator diatas (Reliability, Responsiveness, Assurance, Empahty, Tangible) diperoleh skor total 249,58 dengan skor rata-rata sebesar $2,50 \%$. Sehingga didapatlah persentase total $56,23 \%$. Dari persentase diatas dapat diartikan bahwa pasien yang datang untuk menebus resep di Instalasi Farmasi Rumah Sakit Umum Daerah Klungkung merasa cukup puas atas pelayanan yang di berikan. Dari nilai kepuasan sebesar 56,23\%, Reliability (kehandalan) sebesar $18 \%$, Responsiveness (cepat tanggap) sebesar 12\%, Assurance (keyakinan) sebesar 26\%, Emphaty (empati) sebesar 23\%, dan Tangible (berwujud) sebesar 21\%, disajikan dalam Gambar 1 berikut.

\section{Perbandingan Tiap Indikator Dalam Nilai Kepuasan Pasien}

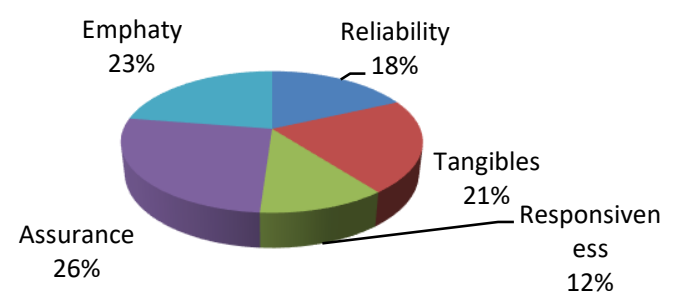

Gambar 1. Diagram Perbandingan Tiap Indikator Dalam Nilai Kepuasan Pasien 


\section{PEMBAHASAN}

Penelitian ini merupakan penelitian yang menggunakan pendekatan analisis deskriptif yang bertujuan memberi gambaran mengenai tingkat kepuasan pasien terhadap pelayanan kefarmasian di Instalasi Farmasi Rumah Sakit Umum Daerah Klungkung. Pengumpulan data dalam penelitian ini menggunakan kuesioner yang dibuat oleh I Made Bambang Suryadinata dengan reliabilitas 0,947 dan Validitas 0,361 dikenakan kepada 100 pasien atau penunggu pasien yang mengambil obat ke Instalasi Farmasi Rumah Sakit Umum Daerah Klungkung.

Dilihat dari skor rata-rata pada indikator reliability (kehandalan) diperoleh skor rata-rata sebesar 2.50 dan diklasifikasikan pasien kurang puas dengan pelayanan kefarmasian yang diberikan petugas. Hal ini dapat ditingkatkan dengan kemampuan dan kehandalan untuk menyediakan pelayanan yang tepat dan benar serta terpercaya. Kehandalan petugas di instalasi farmasi berhubungan dengan pengobatan pasien. Dengan pelayanan yang tepat dan benar serta terpercaya dapat mengurangi terjadinya kesalahan pengobatan, misalnya kesesuaian obat yang diserahkan kepada pasien serta pemberian informasi obat yang meliputi indikasi, waktu pemakaian, efek samping dan tempat penyimpanan obat.

Pada indikator tangible (berwujud) diperoleh skor rata-rata sebesar 2.67 dan diklasifikasikan pasien cukup puas dengan pelayanan kefarmasian yang diberikan petugas. Hal ini dapat ditingkatkan dengan penyediaan pelayanan berupa sarana fisik perkantoran, komputerisasi administrasi, ruang tunggu dan tempat informasi.

Pada indikator responsiveness (cepat tanggap) sebesar 1,44 dan diklasifikasikan pasien tidak puas terhadap pelayanan kefarmasian yang diberikan petugas. Hal ini dapat ditingkatkan dengan kesanggupan untuk membantu dan menyediakan pelayanan secara cepat dan tepat serta tanggap terhadap keinginan pasien.

Pada indikator assurance (keyakinan) diperoleh skor rata-rata sebesar 3,29 dan diklasifikasikan pasien cukup puas dengan pelayanan kefarmasian yang diberikan petugas. Hal ini dapat ditingkatkan dengan kemampuan dan keramahan serta sopan santun pegawai dalam meyakinkan kepercayaan pasien.

Pada indikator empaty (empati) diperoleh skor rata-rata sebesar 2,81 dan diklasifikasikan konsumen cukup puas dengan pelayanan kefarmasian yang diberikan petugas. Hal ini dapat ditingkatkan dengan sikap tegas tetapi penuh perhatian dari pegawai terhadap pasien.
Pada grafik tingkat kepuasan pasien diperoleh skor rata-rata sebesar $2 \%$ diklasifikasikan pasien kurang puas dan $98 \%$ diklasifikasikan cukup puas, dan jika ditotal mendapatkan nilai rata-rata 2,50 dimana menurut tabel klasifikasi persepsi pasien masuk kategori kurang puas. Melihat klasifikasi persentanse seperti di atas menggambarkan bahwa pasien belum kurang puas akan pelayanan kefarmasian di Instalasi Farmasi RSUD Klungkung, oleh karena itu harus lebih ditingkatkan baik dari segi fasilitas, pengelolaan obat dan pelayanan petugas kepada pasien sehingga tingkat kepuasan pasien meningkat.

Dari kelima indikator di atas, Indikator Responsiveness mendapat nilai paling rendah. Maka hendaknya para pegawai Instalasi Farmasi Rumah Sakit Umum Daerah Klungkung lebih tanggap lagi dengan pasien atau keluarga pasien yang ingin mengambil obat atau membeli obat di Instalasi Farmasi Rumah Sakit Umum Daerah klungkung. Selain itu, para pegawai di Instalasi Farmasi juga hendaknya lebih sopan dalam memberikan pelayanan. Ruang tunggu juga dibuat lebih nyaman lagi dengan diberikan aneka tumbuhan hias dan diberikan tempat duduk yang bersih serta memadai juga dapat mempengaruhi kepuasan pasien yang datang ke Instalasi Farmasi Rumah Sakit Umum Daerah Klungkung.

\section{SIMPULAN}

Berdasarkan penelitian tingkat kepuasan terhadap pelayanan kefarmasian di Instalasi Farmasi RSUD Kabupaten Klungkung yang telah dilakukan, pelayanan kefarmasian Instalasi Farmasi RSUD Kabupaten Klungkung memperoleh hasil pada Responsiveness memiliki persentase $28,80 \%$, Assurance memiliki persentase 65,88\%, Empathy memiliki persentase 56,23\% dan indikator Tangible memiliki persentase 53,33\%. Reliability 45,33\%, Sehingga dapat disimpulkan bahwa pasien merasa puas dengan pelayanan yang telah didapatkan di Instalasi Farmasi dengan nilai rata-rata kepuasan mencapai 2,50 yang dalam dalam tabel Klasifikasi Persepsi Pasien masuk klasifikasi kurang puas. Jadi dapat disimpulkan bahwa pasien merasa kurang puas dengan pelayanan kefarmasian di Instalasi Farmasi Rumah Sakit Umum Klungkung. 


\section{DAFTAR PUSTAKA}

Depkes RI, 2004, Surat Keterangan Menteri Kesehatan Republik Indonesia No. 1197/MENKES/SK/X/2004, Tentang Standar Pelayanan Farmasi di Rumah Sakit, Jakarta.

Depkes RI, 2009, Undang-Undang Republik Indonesia No. 44 Tahun2009, Tentang Rumah Sakit, Jakarta.
Hastono, SP, 2011, Analisis Data Jakarta, Penerbit Pustaka Fakultas Kedokteran Masyarat-UI

Mulyono, S 1991. Operational Research. FE-UI. Jakarta.

Suryawati. C, 2004 Kepuasan Pasien Rumah Sakit (tinjauan teoritis dan penerapannya pada penelitian jurnal JMPK/Vol;07/No: 04/Desember 2004. Diakses pada tanggal 12 Juni 2016. 